\title{
Angiotensin-I-Converting Enzyme (ACE) Inhibitors from Marine Resources: Prospects in the Pharmaceutical Industry
}

\section{Isuru Wijesekara ${ }^{1}$ and Se-Kwon Kim ${ }^{1,2, *}$}

1 Marine Biochemistry Laboratory, Department of Chemistry, Pukyong National University, Busan 608-737, Korea; E-Mail: isurumatara@yahoo.com (I.W.)

2 Marine Bioprocess Research Center, Pukyong National University, Busan 608-737, Korea

* Author to whom correspondence should be addressed; E-Mail: sknkim@pknu.ac.kr; Tel.: +82-51-629-7094; Fax: +82-51-629-7099.

Received: 19 February 2010, in revised form: 8 March 2010 / Accepted: 29 March 2010 / Published: 31 March 2010

\begin{abstract}
Hypertension or high blood pressure is one of the major independent risk factors for cardiovascular diseases. Angiotensin-I-converting enzyme (EC 3.4.15.1; ACE) plays an important physiological role in regulation of blood pressure by converting angiotensin I to angiotensin II, a potent vasoconstrictor. Therefore, the inhibition of ACE activity is a major target in the prevention of hypertension. Recently, the search for natural ACE inhibitors as alternatives to synthetic drugs is of great interest to prevent several side effects and a number of novel compounds such as bioactive peptides, chitooligosaccharide derivatives (COS) and phlorotannins have been derived from marine organisms as potential ACE inhibitors. These inhibitory derivatives can be developed as nutraceuticals and pharmaceuticals with potential to prevent hypertension. Hence, the aim of this review is to discuss the marine-derived ACE inhibitors and their future prospects as novel therapeutic drug candidates for treat hypertension.
\end{abstract}

Keywords: angiotensin-I-converting enzyme inhibitors; antihypertensive activity; bioactive peptides; chitooligosaccharides; hypertension; phlorotannins

Abbreviations: ACE; angiotensin-I-converting enzyme; COS; chitooligosaccharides; AE-COS; aminoethyl chitooligosaccharides 


\section{Introduction}

Hypertension or high blood pressure is one of the major independent risk factors for cardiovascular diseases [1,2] and it is a major health issue, estimated to be affecting about $20 \%$ of the world's adult population [3]. Among processes related to hypertension, angiotensin-I-converting enzyme (ACE) plays an important role in the regulation of blood pressure. ACE is a dipeptidyl carboxypeptidase (EC. 3.4.15.1) and was originally isolated from horse blood [4]. It plays a crucial role in the regulation of blood pressure as it promotes the conversion of angiotensin-I to the potent vasoconstrictor angiotensin-II as well as inactivates the vasodilator bradykinin, which has a depressor action in the renin-angiotensin system. This potent vasoconstrictor is also involved in the release of a Na-retaining steroid, aldosterone from the adrenal cortex, which has a tendency to increase blood pressure [5].

Inhibition of ACE is considered to be a useful therapeutic approach in the treatment of hypertension. Therefore, in the development of drugs to control high blood pressure, ACE inhibition has become an important activity. Many studies have been attempted in the synthesis of ACE inhibitors such as captopril, enalapril, alcacepril and lisinopril, which are currently used in the treatment of essential hypertension and heart failure in humans [6]. However, these synthetic drugs are believed to have certain side effects such as cough, taste disturbances, skin rashes or angioneurotic edema all of which might be intrinsically linked to synthetic ACE inhibitors [7]. Therefore, the research and development to find safer, innovative, and economical ACE inhibitors is necessary for the prevention and remedy of hypertension [8,9]. Many research groups have combed for novel ACE inhibitors from natural products [10], microbial sources [11] and food proteins [12].

Marine organisms are rich sources of structurally diverse bioactive compounds. Hence, a great interest has been developed nowadays to isolate bioactive compounds, which act as ACE inhibitors from marine resources because of their numerous health beneficial effects. According to the researches, it has reported that marine-derived bioactive peptides, chitooligosaccharide derivatives (COS) and phlorotannins have potent ACE inhibitory activity. This review discusses the above three groups of marine-derived ACE inhibitors and their inhibitory properties, emphasizing their potential application as future pharmaceuticals to prevent hypertension.

\section{Marine-derived ACE Inhibitors and Their Antihypertensive Activity}

\subsection{Bioactive peptides}

Components of proteins in food are containing sequences of bioactive peptides, which could exert a physiological effect in the body. These short chains of amino acids are inactive within the sequence of the parent protein, but can be released during gastrointestinal digestion, food processing, or fermentation. Marine-derived bioactive peptides have been obtained widely by enzymatic hydrolysis of marine proteins [13-17]. In fermented marine food sauces such as blue mussel sauce and oyster sauce, enzymatic hydrolysis has already been done by microorganisms, and bioactive peptides can be purified without further hydrolysis [18,19]. In addition, several bioactive peptides have been isolated from marine processing by-products or wastes [20-23]. Marine by-products generated during marine food processing, have low commercial value, but the detection of in vitro ACE inhibitory activity in these products might provide significant environmental and cost benefits. Marine-derived bioactive 
peptides have been shown to possess many physiological functions, including antihypertensive or ACE inhibition [24], antioxidant [25,26], anticoagulant [27,28], and antimicrobial [29,30] activities. Moreover, some of these bioactive peptides have identified to possess nutraceutical potentials that are beneficial in human health promotion [31] and recently the possible roles of food-derived bioactive peptides in reducing the risk of cardiovascular diseases has been shown [32].

Marine-derived antihypertensive peptides have shown potent ACE inhibitory activities (Table 1). The potency of these marine-derived peptides to inhibit ACE activity has been expressed as an $\mathrm{IC}_{50}$ value, which is the ACE inhibitor concentration, leading to 50\% inhibition of ACE activity. Moreover, the inhibition modes of ACE-catalyzed hydrolysis of these antihypertensive peptides have been determined by Lineweaver-Burk plots.

Table 1. ACE inhibitory peptides derived from marine organisms: source, enzyme used for hydrolysis, and $\mathrm{IC}_{50}$ value.

\begin{tabular}{llll}
\hline Source & Enzyme & IC $_{\mathbf{5 0}}$ & Ref. \\
\hline Blue mussel sauce & natural fermentation & $19.34 \mu \mathrm{g} / \mathrm{mL}$ & {$[19]$} \\
Alaska pollack & pronase, flavourzyme & $0.21 \mathrm{mg} / \mathrm{mL}$ & {$[33]$} \\
Alaska pollack & alcalase, pronase, collagenase & $2.6 \mu \mathrm{M}$ & {$[34]$} \\
Big eye tuna (muscle) & pepsin & $21.6 \mu \mathrm{M}$ & {$[35]$} \\
Big eye tuna (frame) & pepsin & $11.28 \mu \mathrm{M}$ & {$[36]$} \\
Shrimp & protease & $0.39 \mu \mathrm{M}$ & {$[37]$} \\
Shrimp & Lactobacillus fermentum enzymes & $3.37 \mathrm{mg} / \mathrm{mL}$ & {$[38]$} \\
Hard clam & protamex & $51 \mu \mathrm{M}$ & {$[39]$} \\
Sea cucumber & bromelain, alcalase, protease & $4.5 \mu \mathrm{M}$ & {$[40]$} \\
Rotifer & alcalase & $9.64 \mu \mathrm{M}$ & {$[41]$} \\
Wakame & pepsin & $21 \mu \mathrm{M}$ & {$[42]$} \\
Microalga & pepsin & $29.6 \mu \mathrm{M}$ & {$[43]$} \\
Yellow fin sole & $\alpha$-chymotrypsin & $22.3 \mu \mathrm{M}$ & {$[44]$} \\
Bonito & thermolysin & $0.32 \mu \mathrm{M}$ & {$[45]$} \\
Sardine & alkaline protease & $0.015 \mathrm{mg} / \mathrm{mL}$ & {$[46]$} \\
Oyster & pepsin & $66 \mu \mathrm{M}$ & {$[47]$} \\
Shark & protease & $1.45 \mu \mathrm{M}$ & {$[48]$} \\
Anchovy fish sauce & natural fermentation & $22 \mu \mathrm{M}$ & {$[49]$} \\
Sea bream & alkaline protease & $0.57 \mathrm{mg} / \mathrm{mL}$ & {$[50]$} \\
\hline
\end{tabular}

According to Lineweaver-Burk plot studies, competitive ACE inhibitory peptides have most frequently reported $[18,36,40]$. These inhibitors can bind to the active site to block it or to the inhibitor binding site that is remote from the active site to alter the enzyme conformation such that the substrate no longer binds to the active sites. Moreover, tryptophan, tyrosine, proline or phenylalanine at the $\mathrm{C}$-terminal and branched-chain aliphatic amino acids at the $\mathrm{N}$-terminal is suitable for peptides to act as competitive inhibitors by binding with ACE [51]. In addition, a non-competitive mechanism has also been observed in some peptides [35,52] and this means that the peptide can combine with an enzyme molecule to produce a dead-end complex, regardless of whether a substrate molecule is bound or not. The hydrophobicity of the N-terminus, which is one of the common features of ACE inhibitory peptides, may contribute to the inhibitory activity [53]. ACE inhibitory peptides are generally short 
chain peptides, often carrying polar amino acid residues like proline. Furthermore, structure-activity relationships among various peptide inhibitors of ACE indicate that binding to ACE is strongly influenced by the C-terminal tripeptide sequence of the substrate, and it is suggested that peptides, which contain hydrophobic amino acids at these positions, are potent inhibitors [54].

Numerous in vivo studies of marine-derived antihypertensive peptides in spontaneously hypertensive rats have shown potent ACE inhibition activity [35,36,40,50] and their systolic blood pressure has reduced significantly after oral administration of peptides. According to Lee et al. [36], a single oral administration (10 $\mathrm{mg} / \mathrm{kg}$ of body weight) of peptide has shown a strong suppressive effect on systolic blood pressure of spontaneously hypertensive rats and this antihypertensive activity was similar with captopril, a commercial antihypertensive drug. Furthermore, they have reported that no side effect observed on rats after administration of antihypertensive peptide. In addition, these marine bioactive peptides exhibit antihypertensive activity in vivo than in vitro. The exact mechanisms underlying this phenomenon have not yet been identified. However, it was suggested that bioactive peptides have higher tissue affinities and are subject to a slower elimination than captopril [45]. The antihypertensive peptide isolated from bonito fish hydrolysate product, has found to be hydrolyzed by ACE to produce a smaller peptide than the initial one, which had 8-fold ACE inhibitory activity compared with the initial peptide [45].

Therefore, marine-derived bioactive peptides have a potential in use as functional ingredients in nutraceuticals and pharmaceuticals due to their effectiveness in both prevention and treatment of hypertension in addition to the nutritive value. Some antihypertensive synthetic commercial drugs are known to produce side effects such as an abnormal elevation of the blood pressure after administration. However, marine-derived bioactive peptides are well tolerated by the body, are not expected to exert any harmful side effects. In addition, cost effective and safe drugs can be produced from marine bioactive peptides, but further studies are needed with clinical trials for these marine-derived antihypertensive peptides.

\subsection{Chitooligosaccharide derivatives (COS)}

Chitin is the second most abundant biopolymer on earth after cellulose and one of the most abundant polysaccharide [55]. It is a glycan of $\beta(1 \rightarrow 4)$-linked $\mathrm{N}$-acetylglucosamine units and it is widely distributed in crustaceans and insects as the protective exo-skeleton and cell walls of most fungi. Chitin is usually prepared from the shells of crabs and shrimps. Chitosan, a partially deacetylated polymer of $\mathrm{N}$-acetylglucosamine, is prepared by alkaline deacetylation of chitin [56]. Chitooligosaccharides (COS) are chitosan derivatives (polycationic polymers comprised principally of glucosamine units) and can be generated via either chemical or enzymatic hydrolysis of chitosan [57-59]. Recently, COS have been the subject of increased attention in terms of their pharmaceutical and medicinal applications [60], due to their missing toxicity and high solubility as well as their positive physiological effects such as ACE enzyme inhibition [61], antioxidant [62], antimicrobial [63], anticancer [64,65], immuno-stimulant [66], antidiabetic [67], hypocholesterolemic [68], hypoglycemic [69], anti-Alzheimer's [70], anticoagulant [71] properties and adipogenesis inhibition [72].

Researches on chitosan and its derivative oligomers have identified their potential to inhibit ACE activity. Even though enough studies have not been carried out, it is presumed that COS may have 
desirable properties to inhibit ACE activity. Recently, marine-derived chitooligosaccharide (COS) derivatives such as hetero-chitooligosaccharides, aminoethyl chitooligosaccharides, chitin derivatives, chitosan trimer oligomers and carboxylated chitooligosaccharides have been reported as potent ACE inhibitors. They are briefly discussed below as well as summarized in Table 2.

Hong et al. [61] studied ACE inhibitory activity of different COS and identified that chitosan trimer is more effective in lowering blood pressure compared to other oligomers. Specifically, the trimer has a lower $\mathrm{IC}_{50}$ value $(0.9 \mu \mathrm{M})$ than most of the other molecular weight COS. In addition, Park et al. [73] reported the ACE inhibitory activities of different molecular weight COS or hetero-COS. ACE inhibitory activity of hetero-COS was dependent on the degree of deacetylation of chitosan. They have tested nine kinds of hetero-COS derivatives; prepared by $90 \%, 75 \%$ and $50 \% \mathrm{~N}$-deacetylated of crab chitin with $40 \% \mathrm{NaOH}$ solution and then each chitosan in to hetero-COS derivatives with relatively high molecular masses (5,000-10,000 Dalton), medium molecular masses (1,000-5,000 Dalton) and low molecular masses (below 1,000 Dalton) by ultrafiltration membrane bioreactor system. Among these hetero-COS, 50\% deacetylated and medium molecular weight (1,000-5,000 Dalton) hetero-COS has exhibited the highest ACE inhibitory activity with the $\mathrm{IC}_{50}$ value of $1.22 \mathrm{mg} / \mathrm{mL}$ (Table 2.) and the inhibition pattern is competitive according to the Lineweaver-Burk plots. These findings suggested that molecular weight and degree of deacetylation of COS are important factors for the ACE inhibitory activity.

Table 2. ACE inhibitory COS derived from marine resources: derivatives and $\mathrm{IC}_{50}$ values.

\begin{tabular}{lcc}
\hline COS derivative & IC $_{\mathbf{5 0}}$ & Ref. \\
\hline Chitosan trimer & $0.9 \mu \mathrm{M}$ & {$[61]$} \\
Chitosan oligosaccharides & $1.22 \mathrm{mg} / \mathrm{mL}$ & {$[73]$} \\
Chitin derivatives & & \\
AEC & $0.064 \mu \mathrm{M}$ & {$[74]$} \\
AEC 50 & $0.038 \mu \mathrm{M}$ & {$[74]$} \\
AEC 90 & $0.103 \mu \mathrm{M}$ & {$[74]$} \\
Aminoethyl-COS (AE-COS) & $0.80 \mu \mathrm{g} / \mathrm{mL}$ & {$[75]$} \\
Captopril $^{\mathrm{a}}$ & $0.1 \mu \mathrm{M}$ & {$[74]$} \\
\multicolumn{2}{c}{}
\end{tabular}

To develop ACE inhibitory chitin derivatives, chitin with different degrees of deacetylation have been chemically modified by grafting 2-chloroethylamino hydrochloride on to chitin at the C-6 position [74]. Among three chitin derivatives, such as aminoethyl-chitin with $10 \%$ deacetylation (AEC), aminoethyl-chitin with 50\% deacetylation (AEC50), and aminoethyl chitin with 90\% deacetylation (AEC90), the strongest ACE inhibitor is aminoethyl-chitin with $50 \%$ deacetylation ( $\mathrm{IC}_{50}$ value, $0.038 \mu \mathrm{M}$ ) and the inhibition is competitive. Captopril was used as the positive control ( $\mathrm{IC}_{50}$ value, $\left.0.1 \mu \mathrm{M}\right)$ in this study. Moreover, in vivo studies have shown that it effectively decreased the systolic blood pressure of spontaneously hypertensive rats in a dose-dependent manner. When comparing with the $\mathrm{IC}_{50}$ values of previous studies, these three water-soluble chitin derivatives have superior ACE inhibitory activity than that of chitosan oligosaccharide derivatives and captopril [74].

Furthermore, the structural properties of chitosan also can be improved by chemical modification to obtain higher active COS derivatives. For example, aminoethyl-COS were synthesized by grafting 
aminoethyl functional group to improve its ACE inhibitory activity [75]. Hydroxyl groups of the pyranose ring structure at different positions are different chemical attractions and hydroxyl group in the C-6 position was successfully replaced by the aminoethyl group because the structure of COS was maintained due to the C-6 hydroxyl group, which shows the highest reactivity for aminoethylation. Here, another advantage they acquired is that the aminoethyl COS derivatives are easily soluble in water. According to Ngo et al. [75], ACE inhibitory activity of aminoethyl-COS (AE-COS) has increased more than that of original COS. At the $2.5 \mu \mathrm{g} / \mathrm{mL}$ concentration, COS and aminoethyl-COS exhibited ACE inhibitory activities of $18.6 \%$ and $89.3 \%$ respectively. Further, a marked dose-dependent inhibitory effect has been reported in both COS and aminoethyl-COS treatment groups.

Similarly, Huang et al. [76] have modified $\mathrm{COS}$ by carboxylation with $-\mathrm{COCH}_{2} \mathrm{CH}_{2} \mathrm{COO}^{-}$groups to obtain specific structural features similar to captopril. ACE inhibitory activity of carboxylated COS enhances its activity with increased substitution degree and competitive inhibition has been observed. Further, improvement in ACE inhibitory activity of carboxylated-COS compared to COS might be due to the electrostatic interactions between positively charged sites of enzymatic and negatively charged carboxyl groups similar to captopril.

In addition to the $\mathrm{ACE}$, it has shown that renin also plays a vital role in the renin-angiotensin system. Renin (or angiotensinogenase), is a rate-limiting enzyme in the renin-angiotensin system. It cleaves plasma angiotensinogen to angiotensin-I, which is further converted by ACE to angiotensin-II. Therefore, the inhibition of renin activity is also an attractive target in hypertension therapy. Park et al. [77] reported that COS have greater potential to inhibit renin activity. According to them, $90 \%$ deacetylated and medium molecular weight (1,000-5,000 Dalton) COS has the strongest renin inhibition ( $\mathrm{IC}_{50}$ value, $0.51 \mathrm{mg} / \mathrm{mL}$ ) and act as a competitive inhibitor. Collectively, it can be suggested that COS derivatives are potent drug candidates for treat hypertension and their therapeutic role in pharmaceutical industry are assured.

\subsection{Phlorotannins}

Phlorotannins are phenolic compounds formed by the polymerization of phloroglucinol or defined as 1,3,5-trihydroxybenzene monomer units and biosynthesized through the acetate-malonate pathway. They are highly hydrophilic components with a wide range of molecular sizes ranging between 126-650,000 Dalton [78]. Marine brown algae and red algae accumulate a variety of phloroglucinolbased polyphenols, as phlorotannins of low, intermediate and high molecular weight containing both phenyl and phenoxy units [79,80]. Among marine algae, Ecklonia cava; an edible brown algae is a rich source of phlorotannins than others [81]. In addition to E. cava, other marine algae such as E. stolonifera, Hizikia fusiforme, Eisenia bicyclis, and Eisenia arborea have been reported for various phlorotannins [81]. Phlorotannins have several health beneficial biological activities including, antioxidant [82], anti-HIV [83], antiproliferative [84], anti-inflammatory [85], radioprotective [86], antidiabetic [87], anti-Alzheimer's disease (acetyl cholinesterase and butyryl cholinesterase inhibitory) [88], antimicrobial [89] and antihypertensive or ACE inhibitory activities (Table 3.). 
Table 3. ACE inhibitory phlorotannins derived from marine resources: phlorotannin/fraction and $\mathrm{IC}_{50}$ value.

\begin{tabular}{lcc}
\hline Phlorotannin/fraction & IC $_{\mathbf{5 0}}$ & Ref. \\
\hline Phlorofucofuroeckol A & $12.74 \mu \mathrm{M}$ & {$[89]$} \\
Flavourzyme digest fraction of E. cava & $0.3 \mu \mathrm{g} / \mathrm{mL}$ & {$[91]$} \\
Methanolic extract of A. flabelliformis & $13.8 \mu \mathrm{g} / \mathrm{mL}$ & {$[92]$} \\
Captopril $^{\mathrm{a}}$ & $0.05 \mu \mathrm{g} / \mathrm{mL}$ & {$[91]$} \\
\hline \multicolumn{2}{c}{${ }^{\mathrm{a}}$ positive control }
\end{tabular}

The ACE inhibitory activity of ten Korean seaweeds including, five Phaeophyta (E. cava, E. stolonifera, Pelvetia siliqousa, H. fusiforme, and Undaria pinnatifida), four Rhodophyta (Gigartina tenella, Gelidium amansii, Chondria crassicaulis, and Porphyra tenera), and one Chlorophyta (Capsosiphon fulvescens) have screened by Jung et al. [90]. The ethanol extracts of E. stolonifera, E. cava, P. siliquosa, U. pinnatifida, and G. tenella exhibited significant inhibitory properties against ACE at more than $50 \%$ inhibition at a concentration of $163.93 \mu \mathrm{g} / \mathrm{mL}$. Moreover, they have found that phlorotannins such as eckol, phlorofucofuroeckol A, and dieckol, which derived from E. stolonifera have shown considerable inhibitory activity against ACE. Among them, phlorofucofuroeckol A is the strongest $\mathrm{ACE}$ inhibitor with an $\mathrm{IC}_{50}$ value of $12.74 \mu \mathrm{M}$. Although current knowledge of relationship between the structure and activity of the active phlorotannins is limited, a closed ring dibenzo-1,4-dioxin moiety may be crucial to the above ACE inhibitory effect. In addition, the ACE inhibitory activity may depend on the degree of polymerization of phlorotannin derivatives.

Polyphenolic compounds inhibit ACE activity through sequestration of the enzyme metal factor, $\mathrm{Zn}^{2+}$ ion [91]. Therefore, it has been assumed that phlorotannins might form a complex associated with proteins or glycoproteins to inhibit the ACE activity. Athukorala \& Jeon [92] have reported that flavourzyme enzymatic digest of $E$. cava, which contains high content of phlorotannins, is a potent ACE inhibitor, exhibited an $\mathrm{IC}_{50}$ of $0.3 \mu \mathrm{g} / \mathrm{ml}$ and captopril, a commercial antihypertensive exhibited an $\mathrm{IC}_{50}$ of $0.05 \mu \mathrm{g} / \mathrm{mL}$. They have hydrolyzed seven marine brown algal species (E. cava, Ishige okamurae, Sargassum fulvellum, Sargassum horneri, Sargassum coreanum, Sargassum thunbergii, and Scytosiphon lomentaria) and analyzed for ACE inhibitory activities. Most of the above algal species showed potent ACE inhibitory activities however, E. cava is the most potent ACE inhibitor among them due to its rich content of phlorotannins.

Furthermore, among twenty-six marine red algae, an aqueous extracts at $20^{\circ} \mathrm{C}$ of Lomentaria catenata and Lithophyllum okamurae have reported for potent $\mathrm{ACE}$ inhibitory activity with $\mathrm{IC}_{50}$ values of $12.21 \mu \mathrm{g} / \mathrm{mL}$ and $13.78 \mu \mathrm{g} / \mathrm{mL}$, respectively [93]. From the methanol extracts at $20{ }^{\circ} \mathrm{C}$, Ahnfeltiopsis flabelliformis possessed the highest ACE inhibitory activity ( $\mathrm{IC}_{50}, 13.8 \mu \mathrm{g} / \mathrm{mL}$ ).

Marine-derived phlorotannins are valuable bioactive compounds and could be introduced for the preparation of novel pharmaceuticals as well as functional foods, and their selection is also a good approach for the treatment or prevention of hypertension. 


\section{Conclusions}

Recently, much attention has been paid by consumers towards natural bioactive compounds as functional ingredients and hence it can be suggested that, marine-derived ACE inhibitors are alternative tools that can contribute to consumer's well-being, by being a part of novel nutraceuticals or pharmaceuticals replacing synthetic drugs. Food bioactive compounds are often effective in promoting health and lead to the reduction of disease risk. Especially, bioactive compounds derived from marine organisms have served as a rich source of health-promoting components. Among them, bioactive peptides, chito-oligosaccharides, and phlorotannins are rich sources of natural health enhancers and this fact implies their potential as a functional ingredient in future nutraceutical and pharmaceutical products. According to presented data, it seems that most $\mathrm{IC}_{50}$ values of COS are lower than peptides and phlorotannins, when comparing the ACE inhibitory activity of these marine-derived ACE inhibitors. Until now, most of these ACE inhibitory activities have been observed in vitro or in mouse model systems. Therefore, further research studies are needed in order to investigate their activity in human subjects. In conclusion, it can be suggested that marine-derived ACE inhibitors such as bioactive peptides, chitooligosaccharides, and phlorotannins are potential therapeutic candidates for prevent hypertension and their involvement in the future pharmaceuticals are promising.

\section{Acknowledgements}

This study was supported by a grant from Marine Bioprocess Research Center of the Marine Bio 21 Project funded by the Ministry of Land, Transport and Maritime, Republic of Korea.

\section{References and Notes}

1. Harris, T.; Cook, E.F.; Kannel, W.; Schatzkin, A.; Goldman, L. Blood pressure experience and risk of cardiovascular disease in the elderly. Hypertension 1985, 7, 118-124.

2. Kannel, W.B.; Higgins, M. Smoking and hypertension as predictors of cardiovascular risk in population studies. J. Hypertens. 1990, 8, S3-S8.

3. Alper, A.B.; Calhoun, D.A.; Oparil, S. Hypertension. In Encyclopedia of Life Sciences; Nature Publishing Group: London, UK; 2001, pp. 1-8.

4. Skeggs, L.T.; Kahn, J.R.; Shumway, N.P. The preparation and function of the hypertensionconverting enzyme. J. Exp. Med. 1956, 103, 295-299.

5. Li, G.H.; Le, G.W.; Shi, Y.H.; Shrestha, S. Angiotensin I - converting enzyme inhibitory peptides derived from food proteins and their physiological and pharmacological effects. Nutr. Res. 2003, 24, 469-486.

6. Ondetti, M.A. Design of specific inhibitors of angiotensin-converting enzyme: New class of orally active antihypertensive agents. Science 1977, 196, 441-444.

7. Atkinson, A.B.; Robertson, J.I.S. Captopril in the treatment of clinical hypertension and cardiac failure. Lancet 1979, 2, 836-839.

8. Goretta, L.A.; Ottaviani, J.I.; Keen, C.L.; Fraga, C.G. Inhibition of angiotensin converting enzyme (ACE) activity by flavan-3-ols and procyanidins. FEBS Lett. 2003, 555, 597-600. 
9. Lee, D.H.; Kim, J.H.; Park, J.S.; Choi, Y.J.; Lee, J.S. Isolation and characterization of a novel angiotensin-I-converting enzyme inhibitory peptide derived from the edible mushroom Tricholoma giganteum. Peptides 2004, 25, 621-627.

10. Maruyama, S.; Miyoshi, S.; Tanaka, H. Angiotensin-I-converting enzyme inhibitor derived from Ficus carica. Agric. Biol. Chem. 1989, 53, 2763-2769.

11. Demain, A.L.; Somkuti, G.A.; Hunter-Cevera, J.C.; Rossmoore, H.W. Novel microbial products for medicine and agriculture. Elsevier Science Publishers: Amsterdam, The Netherlands; 1989.

12. Fujita, H.; Yokoyama, K.; Yoshikawa, M. Classification and antihypertensive activity of angiotensin I-converting enzyme inhibitory peptides derived from food proteins. J. Food Sci. 2000, 65, 564-569.

13. Je, J.Y.; Qian, Z.J.; Lee, S.H.; Byun, H.G.; Kim, S.K. Purification and antioxidant properties of bigeye tuna (Thunnus obesus) dark muscle peptide on free radical-mediated oxidation systems. J. Med. Food. 2008, 11, 629-637.

14. Sheih, I.C.; Fang, T.J.; Wu, T.K. Isolation and characterization of a novel angiotensin I-converting enzyme (ACE) inhibitory peptide from the algae protein waste. Food Chem. 2009, $115,279-284$.

15. Slizyte, R.; Mozuraityte, R.; Martinez-Alvarez, O.; Falch, E.; Fouchereau-Peron, M.; Rustad, T. Functional, bioactive and antioxidative properties of hydrolysates obtained from cod (Gadus morhua) backbones. Process Biochem. 2009, 44, 668-677.

16. Suetsuna, K.; Chen, J.R. Identification of antihypertensive peptides from peptic digest of two microalgae, Chlorella vulgaris and Spirulina platensis. Mar. Biotechnol. 2001, 3, 305-309.

17. Zhao, Y.; Li, B.; Liu, Z.; Dong, S.; Zhao, X.; Zeng, M. Antihypertensive effect and purification of an ACE inhibitory peptide from sea cucumber gelatin hydrolysate. Process Biochem. 2007, 42, 1586-1591.

18. Je, J.Y.; Park, J.Y.; Jung, W.K.; Park, P.J.; Kim, S.K. Isolation of angiotensin I converting enzyme (ACE) inhibitor from fermented oyster sauce, Crassostrea gigas. Food Chem. 2005, 90, 809-814.

19. Je, J.Y.; Park, P.J.; Byun, H.K.; Jung, W.K.; Kim, S.K. Angiotensin I converting enzyme (ACE) inhibitory peptide derived from the sauce of fermented blue mussel, Mytilus edulis. Bioresour. Technol. 2005, 96, 1624-1629.

20. Kim, S.K.; Choi, Y.R.; Park, P.J.; Choi, J.H.; Moon, S.H. Screening of biofunctional peptides from cod processing wastes. J. Korean Soc. Agric. Chem. Biotechnol. 2000, 33, 198-204.

21. Kim, S.K.; Kim, Y.T.; Byun, H.G.; Nam, K.S.; Joo, D.S.; Shahidi, F. Isolation and characterization of antioxidative peptides from gelatin hydrolysate of Alaska pollack skin. $J$. Agric. Food Chem. 2001, 49, 1984-1989.

22. Jun, S.Y.; Park, P.J.; Jung, W.K.; Kim, S.K. Purification and characterization of an antioxidative peptide from enzymatic hydrolysates of yellowfin sole (Limanda aspera) frame protein. Eur. Food Res. Technol. 2004, 219, 20-26.

23. Ravallec, P.R.; Charlot, C.; Pires, C.; Braga, V.; Batista, I.; Wormhoudt, A.V.; Gal, Y.L.; Fouchereau-Peron, M. The presence of bioactive peptides in hydrolysates prepared from processing waste of sardine (Sardina pilchardus). J. Sci. Food Agric. 2001, 81, 1120-1125. 
24. Yokoyama, K.H.; Chiba, H.; Yoshikawa, M. Peptide inhibitors for angiotensin-I-converting enzyme from thermolysin digest of dried bonito. Biosci. Biotechnol. Biochem. 1992, 56, 1541-1545.

25. Kim, S.Y.; Je, J.Y.; Kim, S.K. Purification and characterization of antioxidant peptide from hoki (Johnius balengerii) frame protein by gastrointestinal digestion. J. Nutr. Biochem. 2007, 18, 31-38.

26. Mendis, E.; Rajapakse, N.; Kim, S.K. Antioxidant properties of a radical-scavenging peptide purified from enzymatically prepared fish skin gelatin hydrolysate. J. Agric. Food Chem. 2005, $53,581-587$.

27. Jo, H.Y.; Jung, W.K.; Kim, S.K. Purification and characterization of a novel anticoagulant peptide from marine echiuroid worm, Urechis unicinctus. Process Biochem. 2008, 43, 179-184.

28. Rajapakse, N.; Jung, W.K.; Mendis, E.; Moon, S.H.; Kim, S.K. A novel anticoagulant purified from fish protein hydrolysate inhibits factor XIIa and platelet aggregation. Life Sci. 2005, 76, 2607-2619.

29. Liu, Z.; Dong, S.; Xu, J.; Zeng, M.; Song, H.; Zhao, Y. Production of cysteine-rich antimicrobial peptide by digestion of oyster (Crassostrea gigas) with alcalase and bromelin. Food Control. 2008, 19, 231-235.

30. Stensvag, K.; Haug, T.; Sperstad, S.V.; Rekdal, O.; Indrevoll, B.; Styrvold, O.B. Arasin 1, a proline-arginine-rich antimicrobial peptide isolated from the spider crab, Hyas araneus. Dev. Comp. Immuno. 2008, 32, 275-285.

31. Defelice, S.L. The nutritional revolution: Its impact on food industry R\&D. Trends Food Sci. Technol. 1995, 6, 59-61.

32. Erdmann, K.; Cheung, B.W.Y.; Schroder, H. The possible roles of food-derived bioactive peptides in reducing the risk of cardiovascular disease. J. Nutr. Biochem. 2008, 19, 643-654.

33. Park, C.H.; Kim, H.J.; Kang, K.T.; Park, J.W.; Kim, J.S. Fractionation and angiotensin I-converting enzyme (ACE) inhibitory activity of gelatin hydrolysates from by-products of Alaska Pollock surimi. Fish. Aqua. Sci. 2009, 12, 79-85.

34. Byun, H.G.; Kim, S.K. Purification and characterization of angiotensin I converting enzyme (ACE) inhibitory peptides from Alaska Pollack (Theragra chalcogramma) skin. Process Biochem. 2001, 36, 1155-1162.

35. Qian, Z.J.; Je, J.Y.; Kim, S.K. Antihypertensive effect of angiotensin I converting enzymeinhibitory peptide from hydrolysates of bigeye tuna dark muscle, Thunnus obesus. J. Agric. Food Chem. 2007, 55, 8398-8403.

36. Lee, S.H.; Qian, Z.J.; Kim, S.K. A novel angiotensin I converting enzyme inhibitory peptide from tuna frame protein hydrolysate and its antihypertensive effect in spontaneously hypertensive rats. Food Chem. 2010, 118, 96-102.

37. He, H.L.; Chen, X.L.; Sun, C.Y.; Zhang, Y.Z.; Zhou, B.C. Analysis of novel angiotensin-Iconverting enzyme inhibitory peptides from protease-hydrolyzed marine shrimp Acetes chinensis. J. Peptide Sci. 2006, 12, 726-733.

38. Wang, Y.K.; He, H.L.; Chen, X.L.; Sun, C.Y.; Zhang, Y.Z.; Zhou, B.C. Production of novel angiotensin I-converting enzyme inhibitory peptides by fermentation of marine shrimp Acetes chinensis with Lactobacillus fermentum SM 605. Appl. Microbiol. Biotechnol. 2008, 79, 785-791. 
39. Tsai, J.S.; Chen, J.L.; Pan, B.S. ACE-inhibitory peptides identified from the muscle protein hydrolysate of hard clam (Meretrix lusoria). Process Biochem. 2008, 43, 743-747.

40. Zhao, Y.; Bafang, L.; Dong, S.; Liu, Z.; Zhao, X.; Wang, J.; Zeng, M. A novel ACE inhibitory peptide isolated from Acaudina molpadioidea hydrolysate. Peptides 2009, 30, 1028-1033.

41. Lee, J.K.; Hong, S.; Jeon, J.K.; Kim, S.K.; Byun, H.G. Purification and characterization of angiotensin I converting enzyme inhibitory peptides from the rotifer, Brachionus rotundiformis. Bioresour. Technol. 2009, 100, 5255-5259.

42. Suetsuna, K.; Nakano, T. Identification of an antihypertensive peptide from peptic digest of wakame (Undaria pinnatifida). J. Nutr. Biochem. 2000, 11, 450-454.

43. Sheih, I.C.; Fang, T.J.; Wu, T.K. Isolation and characterization of a novel angiotensin I-converting enzyme (ACE) inhibitory peptide from the algae protein waste. Food Chem. 2009, $115,279-284$.

44. Jung, W.K.; Mendis, E.; Je, J.Y.; Park, P.J.; Son, B.W.; Kim, H.C.; Choi, Y.K.; Kim, S.K. Angiotensin I-converting enzyme inhibitory peptide from yellowfin sole (Limanda aspera) frame protein and its antihypertensive effect in spontaneously hypertensive rats. Food Chem. 2006, 94, 26-32.

45. Fujita, H.; Yoshikawa, M. LKPNM: A prodrug-type ACE-inhibitory peptide derived from fish protein. Immunopharmacology 1999, 44, 123-127.

46. Matsui, T.; Matsufuji, H.; Seki, E.; Osajima, K.; Nakashima, M.; Osajima, Y. Inhibition of angiotensin I-converting enzyme by Bacillus licheniformis alkaline protease hydrolysates derived from sardine muscle. Biosci. Biotech. Biochem. 1993, 57, 922-925.

47. Wang, J.; Hu, J.; Cui, J.; Bai, X.; Du, Y.; Miyaguchi, Y.; Lin, B. Purification and identification of a ACE inhibitory peptide from oyster proteins hydrolysate and the antihypertensive effect of hydrolysate in spontaneously hypertensive rats. Food Chem. 2008, 111, 302-308.

48. Wu, H.; He, H.L.; Chen, X.L.; Sun, C.Y.; Zhang, Y.Z.; Zhou, B.C. Purification and identification of novel angiotensin-I-converting enzyme inhibitory peptides from shark meat hydrolysate. Process Biochem. 2008, 43, 457-461.

49. Ichimura, T.; Hu, J.; Aita, D.Q.; Maruyama, S. Angiotensin I-converting enzyme inhibitory activity and insulin secretion stimulative activity of fermented fish sauce. J. Biosci. Bioeng. 2003, 96, 496-499.

50. Fahmi, A.; Morimura, S.; Guo, H.C.; Shigematsu, T.; Kida, K.; Uemura, Y. Production of angiotensin I converting enzyme inhibitory peptides from sea bream scales. Process Biochem. 2004, 39, 1195-1200.

51. Cheung, H.S.; Chushman, D.W. Spectrophotometric assay and properties of the angiotensinconverting enzyme of rabbit lung. Biochem. Pharmacol. 1971, 20, 1637-1648.

52. Suetsuna, K.; Nakano, T. Identification of an antihypertensive peptide from peptic digest of wakame (Undaria pinnatifida). J. Nutr. Biochem. 2000, 11, 450-454.

53. Rho, S.J.; Lee, J.S.; Chung, Y.I.; Kim, Y.W.; Lee, H.G. Purification and identification of an angiotensin I-converting enzyme inhibitory peptide from fermented soybean extract. Process Biochem. 2009, 44, 490-493. 
54. Qian, Z.J.; Jung, W.K.; Lee, S.H.; Byun, H.G.; Kim, S.K. Antihypertensive effect of an angiotensin I-converting enzyme inhibitory peptide from bullfrog (Rana catesbeiana Shaw) muscle protein in spontaneously hypertensive rats. Process Biochem. 2007, 42, 1443-1448.

55. Shahidi, F.; Arachchi, J.K.V.; Jeon, Y.J. Food applications of chitin and chitosans. Trends Food Sci. Technol. 1999, 10, 37-51.

56. Kim, S.K.; Nghiep, N.D.; Rajapakse, N. Therapeutic prospectives of chitin, chitosan and their derivatives. J. Chitin Chitosan 2006, 11, 1-10.

57. Dou, J.L.; Tan, C.Y.; Du, Y.G.; Bai, X.F.; Wang, K.Y.; Ma, X.J. Effects of chitooligosaccharides on rabbit neutrophils in vitro. Carbohydr. Polym. 2007, 69, 209-213.

58. Jeon, Y.J.; Kim, S.K. Continuous production of chitooligosaccharides using a dual reactor system. Process Biochem. 2000, 35, 623-632.

59. Jeon, Y.J.; Kim, S.K. Production of chitooligosaccharides using ultrafiltration membrane reactor and their antibacterial activity. Carbohydr. Polym. 2000, 41, 133-141.

60. Kim, S.K.; Rajapakse, N. Enzymatic production and biological activities of chitosan oligosaccharides (COS): A review. Carbohydr. Polym. 2005, 62, 357-368.

61. Hong, S.P.; Kim, M.H.; Oh, S.W.; Han, C.H.; Kim, Y.H. ACE inhibitory and antihypertensive effect of chitosan oligosaccharides in SHR. Korean J. Food Sci. Technol. 1998, 30, 1476-1479.

62. Park, P.J.; Je, J.Y.; Kim, S.K. Free radical scavenging activity of chitooligosaccharides by electron spin resonance spectrometry. J. Agric. Food Chem. 2003, 51, 4624-4627.

63. Park, P.J.; Lee, H.K.; Kim, S.K. Preparation of hetero-chitooligosaccharides and their antimicrobial activity on Vibrio parahaemolyticus. J. Microbiol. Biotechnol. 2004, 14, 41-47.

64. Shen, K.T.; Chen, M.H.; Chan, H.Y.; Jeng, J.H.; Wang, Y.J. Inhibitory effects of chitooligosaccharides on tumor growth and metastasis. Food Chem. Toxicol. 2009, 47, 1864-1871.

65. Jeon, Y.J.; Kim, S.K. Antitumor activity of chitosan oligosaccharides produced in ultrafiltration membrane reactor system. J. Microbiol. Biotechnol. 2002, 12, 503-507.

66. Jeon, Y.J.; Kim, S.K. Potential immuno-stimulating effect of antitumoral fraction of chitosan oligosaccharides. J. Chitin Chitosan 2001, 6, 163-167.

67. Liu, B.; Liu, W.S.; Han, B.Q.; Sun, Y.Y. Antidibetic effects of chito-oligosaccharides on pancreatic islet cells in streptozotocin-induced diabetic rats. World J. Gastroenterol. 2007, 13, $725-731$.

68. Kim, K.N.; Joo, E.S.; Kim, K.I.; Kim, S.K.; Yang, H.P.; Jeon, Y.J. Effect of chitosan oligosaccharides on cholesterol level and antioxidant enzyme activities in hypercholesterolemic rat. J. Korean Soc. Food Sci. Nutr. 2005, 34, 36-41.

69. Miura, T.; Usami, M.; Tsuura, Y.; Ishida, H.; Seino, Y. Hypoglycemic and hypolipidemic effect of chitosan in normal and neonatal streptozotocin-induced diabetic mice. Biol. Pharm. Bull. 1995, $18,1623-1625$.

70. Yoon, N.Y.; Ngo, D.N.; Kim, S.K. Acetylcholinesterase inhibitory activity of novel chitooligosaccharide derivatives. Carbohydr. Polym. 2009, 78, 869-872.

71. Park, P.J.; Je, J.Y.; Jung, W.K.; Kim, S.K. Anticoagulant activity of heterochitosans and their oligosaccharide sulfates. Eur. Food Res. Technol. 2004, 219, 529-533. 
72. Cho, E.J.; Rahman, A.; Kim, S.W.; Baek, Y.M.; Hwang, H.J.; Oh, J.Y.; Hwang, H.S.; Lee, S.K.; Yun, J.W. Chitosan oligosaccharides inhibit adipogenesis in 3T3-L1 adipocytes. J. Microbiol. Biotechnol. 2008, 18(1), 80-87.

73. Park, P.J.; Je, J.Y.; Kim, S.K. Angiotensin I converting enzyme (ACE) inhibitory activity of hetero-chitooligosaccharides prepared from partially different deacetylated chitosans. J. Agric. Food Chem. 2003, 51, 4930-4934.

74. Je, J.Y.; Park, P.J.; Kim, B.; Kim, S.K. Antihypertensive activity of chitin derivatives. Biopolymers 2006, 83, 250-254.

75. Ngo, D.N.; Qian, Z.J.; Je, J.Y.; Kim, M.M.; Kim, S.K. Aminoethyl chitooligosaccharides inhibit the activity of angiotensin converting enzyme. Process Biochem. 2008, 43, 119-123.

76. Huang, R.; Mendis, E.; Kim, S.K. Improvement of ACE inhibitory activity of chitooligosaccharides (COS) by carboxyl modifications. Bioorg. Med. Chem. 2005, 13, 3649-3655.

77. Park, P.J.; Ahn, L.B.; Jeon, Y.J.; Je, J.Y. Renin inhibition activity by chitooligosacharides. Bioorg. Med. Chem. Lett. 2008, 18, 2471-2474.

78. Ragan, M.A.; Glombitza, K.W. Handbook of physiological methods. Cambridge University Press: Cambridge, UK, 1986; pp. 129-241.

79. Singh, I.P.; Bharate, S.B. Phloroglucinol compounds of natural origin. Nat. Prod. Rep. 2006, 23, $558-591$.

80. Glombitza, K.W.; Li, S.M. Hydroxyphlorethols from the brown alga Carpophyllum maschalocarpum. Phytochemistry 1991, 30, 2741-2745.

81. Heo, S.J.; Park, E.U.; Lee, K.W.; Jeon, Y.J. Antioxidant activities of enzymatic extracts from brown seaweeds. Bioresour. Technol. 2005, 96, 1613-1623.

82. Li, Y.; Qian, Z.J.; Ryu, B.M.; Lee, S.H.; Kim, M.M.; Kim, S.K. Chemical components and its antioxidant properties in vitro: An edible marine brown alga, Ecklonia cava. Bioorg. Med. Chem. 2009, 17, 1963-1973.

83. Artan, M.; Li, Y.; Karadeniz, F.; Lee, S.H.; Kim, M.M.; Kim, S.K. Anti-HIV-1 activity of phloroglucinol derivative, 6,6'-bieckol, from Ecklonia cava. Bioorg. Med. Chem. 2008, 16, 7921-7926.

84. Kong, C.S.; Kim, J.A.; Yoon, N.Y.; Kim, S.K. Induction of apoptosis by phloroglucinol derivative from Ecklonia cava in MCF-7 human breast cancer cells. Food. Chem. Toxicol. 2009, 47, 1653-1658.

85. Jung, W.K.; Ahn, Y.W.; Lee, S.H.; Choi, Y.H.; Kim, S.K.; Yea, S.S.; Choi, I.; Park, S.G.; Seo, S.K.; Lee, S.W.; Choi, I.W. Ecklonia cava ethanolic extracts inhibit lipopolysaccharide-induced cyclooxygenase- 2 and inducible nitric oxide synthase expression in BV2 microglia via the MAP kinase and NF-kB pathways. Food Chem. Toxicol. 2009, 47, 410-417.

86. Zhang, R.; Kang, K.A.; Piao, M.J.; Ko, D.O.; Wang, Z.H.; Lee, I.K.; Kim, B.J.; Jeong, Y.I.; Shin, T.; Park, J.W.; Lee, N.H.; Hyun, J.W. Eckol protects V79-4 lung fibroblast cells against v́-ray radiation-induced apoptosis via the scavenging of reactive oxygen species and inhibiting of the cJun $\mathrm{NH}_{2}$-terminal kinase pathway. Eur. J. Pharmacol. 2008, 591, 114-123.

87. Lee, S.H.; Li, Y.; Karadeniz, F.; Kim, M.M.; Kim, S.K. $\alpha$-Glycosidase and $\alpha$-amylase inhibitory activities of phloroglucinal derivatives from edible marine brown alga, Ecklonia cava. J. Sci. Food Agric. 2009, doi 10.1002/jsfa.3623. 
88. Yoon, N.Y.; Lee, S.H.; Li, Y.; Kim, S.K. Phlorotannins from Ishige okamurae and their acetyland butyry-lcholinesterase inhibitory effects. J. Func. Foods. 2009, 1, 331-335.

89. Nagayama, K.; Iwamura, Y.; Shibata, T.; Hirayama, I.; Nakamura, T. Bactericidal activity of phlorotannins from the brown alga Ecklonia kurome. J. Antimicrob. Chemother. 2002, 50, 889-893.

90. Jung, H.A.; Hyun, S.K.; Kim, H.R.; Choi, J.S. Angiotensin-converting enzyme I inhibitory activity of phlorotannins from Ecklonia stolonifera. Fisheries Sci. 2006, 72, 1292-1299.

91. Liu, J.C.; Hsu, F.L.; Tsai, J.C.; Chan, P.; Liu, J.Y.H.; Thomas, G.N.; Tomlinsond, B.; Loe, M.-Y.; Linf, J.-Y. Antihypertensive effects of tannins isolated from traditional Chinese herbs as nonspecific inhibitors of angiotensin converting enzyme. Life Sci. 2003, 73, 1543-1555.

92. Athukorala, Y.; Jeon, Y.J. Screening for Angiotensin 1-converting enzyme inhibitory activity of Ecklonia cava. J. Food Sci. Nutr. 2005, 10, 134-139.

93. Cha, S.H.; Lee, K.W.; Jeon, Y.J. Screening of extracts from red algae in Jeju for potentials marine angiotensin-I converting enzyme (ACE) inhibitory activity. Algae 2006, 21, 343-348.

(C) 2010 by the authors; licensee Molecular Diversity Preservation International, Basel, Switzerland. This article is an open-access article distributed under the terms and conditions of the Creative Commons Attribution license (http://creativecommons.org/licenses/by/3.0/). 